This is the accepted manuscript of the article, which has been published in

Science, Technology, and Human Values. 2019, 44(6), 1020-1047.

https://doi.org/10.1177/0162243918822741

\title{
THE POWER OF PEER REVIEW ON TRANSDISCIPLINARY DISCOVERY
}

\section{Abstract (193 words)}

This study examines the tension between the academic evaluation system and the development of unconventional research agendas. Whilst scholars have studied the evaluation of research that crosses disciplinary boundaries from the perspective of peer reviewers, they have paid comparatively little attention to the experiences of the performers of unconventional science. This study asks how researchers develop unconventional research agendas to address a long-standing health problem and, in the process, make sense of the actions of a site visit committee organized to advise a foundation funding the project. The study develops a process narrative on the development of a specific transdisciplinary team proposing to study premature birth. The findings show that when the performers and the evaluators of unconventional science developed competing understandings of the research agenda, transdisciplinary discovery became limited as a particular research topic became taboo. Yet, the study also reveals how the performers of unconventional science challenged the power of the site visit committee by making it seem as though they followed the committee's decisions. These findings raise questions about the role of private foundations as funders of academic research and the suitability of traditional evaluation procedures for assessing transdisciplinary discovery.

Key words: peer review, evaluation, transdisciplinary science, medical research, research agenda, research problem. 


\section{INTRODUCTION}

Peer review is one key factor that influences scientific work. Its purpose is to evaluate scientific work for its relevance, correctness of procedures, plausibility of results, and worthiness for scarce resources (Chubin and Hackett 1990). Peer review is part of several key academic tasks and functions: assessment of doctoral dissertations, staff hiring and career promotion in universities, distribution of research funding, journal publishing, scientific awards, evaluation of research organizations, and assessment of future research strategies (Langfeldt and Kyvik 2010). As peer review procedures are present throughout academic careers and the evolution of research projects, they structure much of what happens in academia (Lamont 2009). Prior research has focused on peer review practices as part of journal submissions (e.g., Overbeke and Wagner 2003; Weller 2001), but recently there has been interest in understanding peer review practices in the context of grant applications (e.g., Wessely 1998; Daniel et al. 2007; Lamont 2009; Huutoniemi 2012).

Peer review has traditionally been a discipline-based practice. Evaluative standards are developed within disciplinary communities and members of the communities use the standards to assess the work of their peers (e.g., Knorr Cetina 1999; Lamont 2009). In any given disciplinary community researchers shift back and forth between the roles of evaluators and performers of science. When the object of evaluation is cross-disciplinary and in some way foreign to peer reviewers, the practice of peer review becomes challenging. Tight disciplinary standards have been described as being insufficient for assessing research that challenges disciplinary organization of knowledge (Porter and Rossini 1985; Travis and Collins 1991). Peer reviewers may be biased against research that crosses disciplinary boundaries, if they prefer mainstream, traditional research (Travis and Collins 1991).

To question the validity of peer review in such a way is an uncomfortable topic, because peer review is seen as "the symbol and guarantor of the autonomy of science" (Chubin and Hackett 1990, 2). Yet, there is an urgent need to understand the tension between the academic evaluation system and the 
development of unconventional research agendas, because cross-disciplinary research endeavors are increasingly promoted within higher education institutions and funding agencies (Boix Mansilla 2006; Jacobs and Frickel 2009; National Science Foundation 2013; National Institutes of Health 2013).

The present study examines the complex relationship between the development of an unconventional research agenda and evaluation procedures in a particular setting: a site visit committee assessing a transdisciplinary research proposal and advising a foundation making funding decisions. According to Bianco et al. (2016), the academic evaluation system and the development of research agendas, conventional or unconventional, are inevitably linked by means of research funding. Whilst scholars have studied the evaluation of cross-disciplinary research proposals from the perspective of peer reviewers, they have paid comparatively little attention to how the performers of unconventional science experience evaluation practices (Langfeldt 2001; Langfeldt 2004; Lamont 2009; Mallard et al. 2009; Lamont and Huutoniemi 2011; Huutoniemi 2012). To advance knowledge on the topic, this study asks how researchers develop unconventional research agendas to address a long-standing health problem and, in the process, make sense of the actions of a site visit committee organized to assess progress and advise a research funder.

I draw on a longitudinal qualitative study of a new transdisciplinary research center formed through a partnership between the school of medicine of a research-focused American university and a foundation to prevent premature birth. ${ }^{\text {i }}$ The center consisted of four research teams that relied on distinct hypotheses, data, and methods for tackling the syndrome. A site visit committee evaluated their scientific work yearly. This study tracks the development of one of the transdisciplinary teams, which proposed to study the role of placenta in premature birth.

By analyzing different kinds of qualitative evidence-meeting observations, transcripts from meeting recordings, semi-structured interviews, and documents - and identifying temporally ordered events, the study develops a process narrative on the development of one transdisciplinary team seeking 
to study the problem of premature birth (Polkinghorne 1988; Maines 1993). The findings show that when the performers and the evaluators of unconventional science develop competing understandings of the research focus at the grant proposal stage, transdisciplinary discovery and the search for new lines of research to understand premature birth can become restricted. At the same time, the study reveals how performers of unconventional science are able to challenge the power of a site visit committee by making it seem as though they follow their recommendations.

I begin by discussing prior research on the connection between the academic evaluation system and the development of research agendas. I then describe the research setting, data collection, and analytical approach. Finally, I draw on qualitative evidence to develop a process narrative on the project's evolution. This narrative covers three stages in the evaluation process: proposal stage, after evaluation, and site visit. The findings raise questions about the role of private foundations as funders of academic research and about the goals of peer review in exploratory research, where the objective is to study a health problem that despite decades of research has remained unresolved.

\section{PEER REVIEW AND THE DEVELOPMENT OF RESEARCH AGENDAS}

How research agendas are developed has always been a key question in the history, sociology, and economics of academic research (Bianco et al. 2016). The forces that influence the development of research agendas are multifold and vary from popular research questions in a given socio-historical context to institutional dynamics relating to how the sciences formulate research puzzles (Merton 1942; Kuhn 1970). Scholars have found that external research funding and research policy objectives influence the direction of academic research (e.g., Whitley 2010; Luukkonen and Thomas 2016). Indeed, private foundations, such as the Rockefeller Foundation, have always been significant players in the field of research funding (e.g., Smith 2009; Schneider 2015; Roelofs 2015). 
Bianco et al. (2016) have argued that by means of research funding, promotion, and reputation, the peer review system and the development of research agendas are inevitably linked. We have a variety of funding sources-governments, universities, and foundations - that have their own goals as well as autonomy over how they organize evaluation and justify the distribution of resources (Bianco et al. 2016). As getting research funding continues to become more competitive, there is much pressure for researchers to be strategic about how they formulate research topics, goals, and methods so that they seem attractive to funding institutions (Ziman 1994; Whitley 2010; Gläser and Laudel 2007).

The link between the academic evaluation system and the development of research agendas is formed when researchers apply for grants and peer reviewers assess their proposals. In prior studies of the evaluation of grant applications, scholars have investigated peer reviewers' decision-making processes, argumentation, and evaluative standards both individually and among panels (e.g., Lamont 2009; Lamont and Huutoniemi 2011). Others have considered how the applicant's status, collaborative networks, prior publications, and similarity or difference to the peer reviewer affect the outcomes of peer reviews (e.g., Ebadi and Schiffauerova 2015; Gallo et al. 2016). These studies show that many factors challenge the impartiality of the academic evaluation system. Relatedly, the academic evaluation system is criticized for the criteria, indicators, and methods of measurement that it relies on (Barré 2010).

A further challenge for the evaluation of grant applications is the promotion of cross-disciplinary research (Boix Mansilla 2006; Jacobs and Frickel 2009; National Science Foundation 2013; National Institutes of Health 2013). Despite the call for more cross-disciplinary research, peer review has remained intellectually conservative (Gillespie et al. 1985; McCullough 1989; Chubin and Hackett 1990; Braben 2004; Langfeldt and Kyvik 2010). While the purpose of peer review is to safeguard scientific knowledge and the autonomy of science, some have argued that the academic evaluation system can also be overly rigid when faced with new knowledge. Peer review structures the knowledge configuration of entire 
fields of research and judges the value of proposed new research against accepted knowledge boundaries (Luukkonen 2012; Meskus et al. 2018).

The tension between the academic evaluation system and the development of unconventional research agendas is irrefutable. Prior work has shed light on how peer reviewers make decisions about cross-disciplinary research proposals in the presence of epistemological differences (Lamont 2009; Lamont and Huutoniemi 2011; Mallard et al. 2009; Huutoniemi 2012). When researchers take on the role of an evaluator, even if the object of evaluation is in some way foreign to them, quality is something they claim to "know" through their prior experience (Lamont 2009; Langfeldt 2004). This knowledge does not have to follow the objectives and evaluation guidelines stated by the research funder, but can be defined at a more personal level.

Researchers, in turn, anticipate the varied external expectations of their work-for instance evaluators' standards. Shore and Wright (2000) argued that peer review encourages researchers to use the standards of the evaluator as a benchmark for scientific work. The authors even related academic evaluation to Foucault's (1977) panopticon model where the constant surveillance creates anxiety in the prison inmates so they begin to scrutinize their own behavior and adopt the norms of conduct desired by the disciplinary institution. In contrast, Leisyte et al. (2010) pointed out that researchers can sometimes resist funders' expectations for research agendas. Researchers can make it seem as though their work follows funders' research agendas or, as evaluators of science, they can manipulate the expectations to their own favor (Leisyte et al. 2010).

Because higher education institutions and funders advocate for cross-disciplinary research agendas, researchers do not have a choice but to try to manage the tension between the academic evaluation system and the development of unconventional research agendas. Although there are varied funding opportunities available to researchers, it is difficult to steer away from funding sources that 
demand untraditional, innovative, and exploratory elements. As a result, researchers have to recognize the power of peer review while trying to develop unconventional research agendas.

\section{RESEARCH SITE}

Inception of the Center

Years before the formation of the transdisciplinary research center, the foundation in question got interested in investing in research that could help in decreasing the rate of premature birth. The foundation organized a conference where renowned scientists - some of who were later recruited to the site visit committee - gave the foundation advice about how to undertake such an effort. Out of this conference emerged the idea of a research center that would house scientists from different fields who could objectively look at the problem of premature birth. The foundation identified a university that could join them in a partnership to form a research center with the goal of studying what leads to premature birth and translating this research into clinical interventions and policy changes.

The foundation asked a senior group of scientists from the university - who later became the center's leadership team — to put together a proposal that would introduce innovative research themes on premature birth. The center's proposal consisted of four research areas. These areas had a methodological focus based on the principal investigator's laboratory, but the participants came from different fields of research and practice. The Placental Function research area explored the role of placenta in premature birth. The Pattern Recognition research area identified and explained premature birth trends using cluster analysis approaches. The Bioinformatics research area studied which biological markers correlated with pregnancy related complications. Finally, the Microbiome research area explored how changes in the mothers' human microbial communities contributed to premature birth. 
The center was expected to report annually to the foundation on its progress and to respond to the recommendations from a site visit committee, which was put together by the foundation's scientific advisers. The site visit committee consisted of scientists from different American research universities. Three of them worked in the fields of genetics and reproductive biology and one scientist was a neurobiologist. The scientific advisers asked these scientists to join the committee, because they were well-known scholars in their fields and they had conducted premature birth related research.

The site visit committee did not receive formal instructions explaining how the foundation expected them to assess the center's proposal and progress. Rather, the committee was informed about the aim of finding the cause of premature birth through transdisciplinary research approach. The committee could use its expertise and judgment to decide what the evaluation should focus on. I do not have observational data from meetings between the committee and the foundation's representatives and so I analyze how the performers of unconventional science experienced the evaluation process.

The center's first evaluation consisted of a submission of the grant proposal, a one-day site visit followed by a written review document from the committee, and the leadership group's written response to the foundation and the committee. These steps were repeated each year as part of the center's annual progress evaluation, after which the foundation and the site visit committee decided on the budget for the next year. The scientists, especially the center's leadership team, commented multiple times that they had never been involved with a grant that required such intensive involvement with the funder and its site visit committee. With their previous NIH grants, for instance, their work had been assessed by a site visit committee at the beginning and at the end of the project, not throughout it.

During the first site visit, members of the foundation and the committee attended a one-day seminar where the scientists presented their proposal to form the center. After the evaluation of the grant proposal and the site visit, the center leadership received a written review that explained what aspects of their proposed efforts were most valuable and what should be changed. The center leadership then 
responded to the critique by preparing a document where they demonstrated how the feedback would be incorporated into the following year's plan. While the center had some leeway when responding to the site visit committee's recommendations, it was dependent on the annual budget from the foundation.

\section{DATA AND ANALYTICAL APPROACH}

The Placental Function research area, which is the focus of the present study, consisted of seven active members, who were tenured professors or postdoctoral scholars from the disciplines of genetics, pathology, and obstetrics and gynecology. The principal investigator's laboratory in the genetics department served as the team's methodological core. The research group specialized in, for instance, microarrays and high-throughput sequencing. The members of the laboratory had previously focused on understanding how genomic mechanisms govern cellular differentiation in the embryo, although this work was new to the collaborators from pathology and obstetrics and gynecology. As is characteristic of transdisciplinary research, the team's shared goal was to combine the practitioners' clinical expertise with the genetics research group's methodological and analytical skills.

As part of the larger project, I amassed various types of data, such as meeting recordings (160 hours), field notes (observations from 120 meetings and events), and interviews (36). I also collected documents that relate to the center's annual reviews (research proposal and progress reports, site visit committee's assessments, and response letters from the leadership team from 2011-2014). For this study, I have analyzed data that helps to explain the development of the Placental Function team from the grant proposal stage to the end of the first funding cycle. Table 1 summarizes the data this study draws on. 
The analysis of these data sources can be divided into three parts (see Figure 1): 1) analysis of the research proposal and its assessment, 2) analysis of the scientific meeting discussions during the first year, and 3) analysis of the progress report and its assessment after the first year. Both the meeting transcripts and documents were analyzed using Atlas.ti qualitative software program.

\section{--- Insert Figure 1 Here ---}

Analysis of the research proposal and its assessment: I began the data analysis by studying the initial grant proposal and the critique from the site visit committee. I also examined interviews with members of the leadership group to inform the analysis of the documents. I had conducted semistructured interviews with members of the center at two different time points: when the center was formed and two years later. The length of each interview varied from 1 to 2 hours and they were transcribed.

To inform the analysis of the grant proposal and the site visit committee's assessment of the Placental Function team's proposed work, I analyzed ten interviews from the first batch, which were conducted with four members from the leadership group, one administrator, and five researchers from the Placental Function team. The interview protocol focused on questions around how the scientist had joined the center, what was his/her team like, how their work related to premature birth, what type of work he/she had done before, and how his/her laboratory operates.

Analysis of the meeting discussions: The center scheduled regular meetings for its leadership team, the four research teams, and two different types of data groups. It also had an investigator meeting that served as an open forum for anyone interested in premature birth. For the present study, I analyzed recordings from the Placental Function team, leadership, and investigator meetings that took place during the first year. During this time, the Placental Function team met four times. In contrast, during the first 
year, the leadership group organized approximately thirty meetings and the open forum for anyone interested in premature birth, the investigator meeting, was organized twenty times.

The regular attendees of the Placental Function team meetings were researchers from the fields of genetics, pathology, and obstetrics and gynecology who actively participated in the research project. The meetings lasted from 60 to 75 minutes and the transcripts were from 35 to 45 pages long. The meeting format was typically such that the principal investigator of the team acted as the chair and one of the postdoctoral researchers presented on the most recent analyses. I read and coded the four Placental Function team meeting transcripts in entirety. While these meeting discussions could have focused on a number of topics, instances in which the meeting participants talked about their chosen research problem and reflected on the peer reviewers' feedback on their research proposal were particularly prevalent.

When examining the leadership and the investigator group meeting transcripts, I selected 16 meeting transcripts based on my own field notes and the timeline of the center's annual review. I focused on meetings that took place a month before and a month after the evaluation of the first funding cycle as in these instances the discussions on the boundaries around premature birth were intensified. They presented the kinds of "hot moments" of evaluation that can reveal the tensions between competing logics existing simultaneously around one research area (Lamont 2012,213). In these meetings, the center leadership planned for the first annual review and discussed how they would adjust the organization according to the site visit committee's critique. In the investigator meetings, the leadership prepared the members of the center for the annual evaluation and explained how the center would be transformed in response to the reviews.

Analysis of the progress report and its assessment: The final step in the analytical process was to examine the annual report the center had prepared regarding the first year's achievements. I focused on how the work of the Placental Function team was presented. I also examined the written feedback the center received and then the written response the leadership prepared. 
To further understand how the evaluations were perceived by the different actors, I analyzed seven interviews from the second batch of interviews that were conducted two years after the center's formation. As the Placental Function team had been cut at this point and as some of their members had since left the university, only two members of the team agreed to be interviewed. The other five interviewees were regular attendees of the leadership group meetings. The interview protocol for the second round of interviews included questions such as how the research efforts had progressed, what were collaborative interactions like, and how had the center evolved in relation to the foundation and its site visit committee.

Development of a process narrative: The analytical stages listed above present events that occurred in a chronological order. The research proposal and its evaluation were followed by different meetings, and after a year the center's research progress was evaluated and again discussed in meetings. A process narrative of the research project's development in relation to the evaluations emerged from an analysis of the temporally ordered events (Polkinghorne 1988; Maines 1993). Without a longitudinal study design it would have been impossible to capture this process. Accordingly, it has been noted that a researcher must tap into the organizational conversation for an extended period of time in order to reveal how a particular process is constructed (Heracleous and Hendry 2000).

Each analytical stage utilized a combination of exotextual and endotextual approaches as the purpose was to move between textual analysis of documents (e.g., research proposal, progress report, and written reviews) and contextual inquiry of meeting interactions (Barry at al. 2006). This meant analyzing the documents side by side with how the performers of science made sense of the documents in given contexts, meetings and interviews. The analysis of documents, and how they were discussed in meetings and interviews, relied on an interactionist coding paradigm. This enabled the identification of the conditions that gave rise to the process narrative, the context in which the events were embedded in, and the strategies by which the actors managed the various events (Lofland and Lofland 1995; Corbin 
and Strauss 2008). Overall, the process narrative was developed inductively through the open coding of the actors' statements both in textual and contextual data (Strauss 1987; Corbin and Strauss 2008).

\section{PROPOSAL STAGE: EXPLORING BOUNDARIES AROUND PREMATURE BIRTH}

Today funding calls tend to underline path-breaking research that seeks to break down disciplinary boundaries and promote new lines of research on a given topic (Luukkonen and Thomas 2016). Similarly, the objective of the foundation was to support the work of scientists who were willing to let go of preexisting biases regarding the study of premature birth and imagine new explanations for the syndrome. A geneticist from the Placental Function team was concerned about the tendency of scholars to classify the problem of premature birth according to their established research lines. He had attended a conference on premature birth where this was evident:

I was at a premature birth meeting and there were four different camps. There were the people who were saying it is all infection and other people saying it was an incompetent cervix, that the cervix is not mechanistically wired correctly and that was the problem. There were all these biomechanics guys. There were people saying it was genetics...So there were camps, there were clear camps. [ID-1]

The foundation hoped that these camps-or tribes as Becher and Trowler (2001) called disciplinary communities - would approach premature birth in new ways that would not be well known in their respected research communities. Moreover, the hope was that the different camps would build collaborative ties across them thus generating new perspectives to the study of premature birth.

In response to the foundation's objectives, the Placental Function team proposed to explore how genetic analyses of placental cells could be used to understand what leads to premature birth. The scientists argued that although previous research had demonstrated that problems with placental 
implantation are associated with premature birth, few studies had explored the genetic mechanisms that underlie the placenta's role in premature birth. ${ }^{\text {ii }}$ Correspondingly, the motivation behind their work was to understand genetic variation in placenta and its connection to different types of placental failure.

In line with transdisciplinary research approach, the team included both scientists and medical practitioners who sought to collaborate throughout the research process (Maasen and Lieven 2006; van der Laan and Boenink 2015). The team proposed that a pathologist would provide the team of geneticists with stored placental tissue samples and related patients' medical records. Then, obstetricians and gynecologists, who specialized in high-risk pregnancies, would help the geneticists to review the medical records and find cases of suitable placental tissue samples, and finally the geneticists would be in charge of the DNA sequencing and data analysis.

The scientists suspected that their findings could lead to a more nuanced clinical categorization of conditions that lead to premature birth. Their proposal emphasized the clinical observation that premature birth is not a homogeneous event in that only one particular condition would lead to a baby being born prematurely. As a clinician investigator from the field of obstetrics and gynecology explained in an interview, "We think that many obstetrical complications, like premature birth and toxemia or preeclampsia, are in a spectrum of things caused by problems with the placenta. They have some common denominators of placental pathology that can cause both of those things. [ID-19]" By identifying the genetic differences that lead to various kinds of placental failure, their proposed study had the potential to result in novel interventions and therapies to prevent premature birth.

The site visit committee did not become convinced by this research proposal. Their concerns were expressed at the first site visit that was held before the award was granted. ${ }^{\mathrm{iii}}$ One team member recounted the event:

I remember from that [the site visit], they [committee] did not like the placenta research area. I think they didn't like the emphasis on preeclampsia, and felt that there should be more on 
spontaneous premature birth. I think after that was when the area was defunded, or the funding was pretty substantially reduced, and then eventually taken away. [ID-16]

Preeclampsia is a pregnancy disorder characterized by high blood pressure and the presence of protein in urine. It is one of the leading causes of maternal and infant illness and death, and the only known treatment is early delivery. Preeclampsia is dangerous for both the mother and the baby, because if left untreated, it can develop into life-threatening seizures. In an interview, the principal investigator explained the connection between placental function and preeclampsia:

Placenta delivers oxygen and nutrients and hormones and whatever else. In preeclampsia, the leading cause of premature birth is that that connection does not work. By the last trimester of pregnancy, when the baby is demanding all this food and all this oxygen, the vessels were not set up to deliver and it causes this big problem. The baby goes into distress. [ID-1]

To prevent the baby from going into distress, and to save the mother, the baby needs to be delivered as soon as possible, but in these instances premature birth is medically indicated-labor induction or cesarean delivery - and not spontaneous and, so to speak, natural. The site visit committee argued that preeclampsia was only one among many conditions that result in medically indicated premature birth and that understanding what causes preeclampsia would not help in addressing spontaneous premature birth, which they saw as important.

The Placental Function team's view of the center's research focus differed, because although preeclampsia led to medically induced early birth, the health risks for the babies were the same as in cases of spontaneous premature birth. A geneticist described how differently the scientists and the site visit committee perceived premature birth: "The funny thing is that when the grant proposal was sent out, the people who reviewed it thought a premature birth should be defined as premature birth when a 
woman goes into labor and gives birth prematurely and this is like natural labor. [ID-9]" The same scientist said:

But if you look at what happens with premature birth is that the babies are too small and they have all these health issues and they have all these mental issues. So, if you are taking them out early, even if the mom isn't going into labor, they are still going to have these issues. From my perspective, and I think from the perspective of others in our team, it really shouldn't matter how the baby is taken out. It should matter why is the baby taken out and we should prevent those problems, because you really want the baby to stay in there longer. [ID-9]

The foundation's objective was to fund new research paths to better understand premature birth, because although there were common conditions that were often linked with an increased risk of premature birth (e.g., multiple pregnancies, infections, diabetes), and although these connections had been widely studied, the cause of premature birth had remained unknown (World Health Organization 2012). The challenge for such a research objective is how to bridge the established lines of research with new lines of research in a productive way. The site visit committee consisted of scholars who had conducted research on premature birth and developed their own views on the problem. A member of the leadership team described how the committee reacted to the proposal to form the center:

These people [site visit committee] were wondering, "what on Earth are these guys [members of the center] doing." They know me and they know the other individuals, but they said "what are you guys doing in premature birth, you're not premature birth experts. There's a whole group that works on that." So it's like we are the newbies, right? We are all well-known scientists but what are these well-known scientist all of the sudden doing in their territory, premature birth? [ID-27] 
For the Placental Function team this meant that they were perceived as studying a health problem they had limited experience in and that they were drawing their own boundaries around what should be included in the transdisciplinary study of the syndrome. When assessing the research proposal, the committee classified the problem of premature birth differently. While the Placental Function team argued that preventing health risks for premature babies in general should be regarded as important, the site visit committee saw the distinction between spontaneous and medically indicated premature birth as crucial. Foucault (1983) wrote about practices of objectification, such as when academic scholars turn different parts of human life into objects of analysis. In a similar manner, the committee sought to classify premature birth according to a clinical notion of spontaneous, as opposed to medically induced delivery, while the scientists' arguments emphasized the importance of preventing human suffering.

\section{AFTER EVALUATION: CHALLENGING PEER REVIEWERS’ PROBLEM DEFINITION}

Despite the site visit committee's directive to cut the team from the center's overall effort, the leadership team worked out a way to fund the research area through other sources. The decision to go against the committee's recommendation was risky, because it could jeopardize their collaborative relationship with the foundation. At the same time, because this was not a typical research grant, the center assumed they had a say in which direction the research agenda should be taken.

The site visit committee's critical evaluation of the problem focus left its mark on the team, however. In the meetings that followed, the Placental Function team challenged the critique and especially the boundaries the committee had established around premature birth during the evaluation of the research proposal. Individuals can resist formal rules and structures through ongoing work processes, such as meeting participation (Strauss et al. 1963). In line with this, all the Placental Function team meetings had an instance where the participants discussed what premature birth looks like, what was the 
view of the site visit committee, and how their own work fit into this perspectives. In the first meeting, for example, the principal investigator addressed the attendees by asking:

What actually does premature birth mean? If we don't get anything else out of this meeting, I think having a discussion about this so that we are all on the same page would be extraordinarily useful. Because I think premature birth is a large spectrum as to reasons that probably have a root cause that is similar...Because one of the major criticisms of our research area was that we spent a lot of time thinking about preeclampsia. And another major criticism was that preeclampsia is not spontaneous premature birth, which I think is not a great way of looking at the problem. [ID1; Placental Function; 051611]

The investigator restated what was the main critique their research proposal received and invited the attendees to share their thoughts on the boundaries around the problem of premature birth. He did not agree with the claim that preeclampsia was an irrelevant area of study and instead suggested that premature birth included multiple diseases that might all have a similar cause. The same investigator stated:

My priority in this meeting is to get our viewpoint about what is premature birth, and what are the classes of premature birth that we are really trying to understand in the context of the center. Whether it's spontaneous, [medically] indicated, all the various subtexts. It would be great if we can have a conversation about that, so that we are all on the same playing field when we are going forward with this effort. [ID-1; Placental Function; 051611]

The scientist emphasized that rather than just taking for granted what the site visit committee said, the team should develop a comprehensive understanding of the premature birth syndrome. Although the principal investigator's statements continuously reflected the committee's feedback, they also suggested 
an effort to become more independent of their expectations. He emphasized that the researchers should develop their own viewpoint so that they are, as a team, "on the same playing field" concerning their research efforts. In order to achieve a shared understanding of premature birth, the principal investigator wanted to educate the participants on the complexities of the topic. He sought to convince the researchers of the importance of having a broader understanding of premature birth by explaining what the various causes were that led to early delivery:

Premature birth is basically divided into these two categories, spontaneous versus indicated. And you can divide the spontaneous up into those that are due to infection, those that are ruptured membranes, and those that are just completely unexplained. Whereas indicated is largely preeclampsia. [ID-1; Placental Function; 051611]

He explained how premature birth cases are typically divided into two categories, spontaneous and indicated. The former meant births that began naturally and the latter referred to births that required a medical intervention. According to the investigator, preeclampsia alone could explain a bulk of the indicated premature birth cases. During the first funding cycle, this piece of information was often used in the team meetings to demonstrate that by studying what leads to preeclampsia, the scientists could address a significant subclass of premature birth.

Six months later, the same investigator continued to set the tone for the meeting by reminding everyone of how complex the phenomenon of premature birth was. He had prepared a presentation with several slides on the different reasons that lead to premature birth and emphasized that it was unknown what caused premature birth.

The take home point is that there is no clear understanding of what causes premature birth. Whether it is the placenta, whether it is the immune system, whether it is just purely mom and 
dad, it is still unknown, let alone the mechanism. We have got a long way to understand even the fundamentals of what is going on here. [ID-1; Placental Function; 110211]

The principal investigator argued that the current knowledge on premature birth was too sparse to decide what the research efforts should focus on. The cause for the syndrome remained unknown, which was one of the reasons the center was formed in the first place. This statement, made in front of the members of his team and the leadership group, was an attempt to undermine the site visit committee's critique. The principal investigator suggested that because no expert in any field had discovered the cause for premature birth, evaluating which research agenda was the most promising was close to an impossible task. In an interview, a member of the leadership team stated that the site visit committee seemed to think that solving premature birth required research on how to control uterine contractions:

The irony is, obstetricians have spent literally 30 years plus working on control of uterine contractions. Tocolytics [medications to suppress premature labor] is the area that most obstetricians have worked on for those three decades. They have found very potent drugs to control uterine contractions, but they still cannot stop premature birth. That is why [scientific adviser of the foundation] said when the center was formed, "Well, that hasn't worked for 30 years, so why do we have to keep doing it?" Yet this external site visit group... focused almost immediately on trying to retain a focus on uterine contractions and cervix and things like that. [ID-27]

According to this leader, while the scientific adviser was convinced that it was necessary to explore new research paths to premature birth, the site visit committee preferred the study of uterine contractions and the cervix. These topics were seen as more conceivable, because they were "closer" to premature birth than, for instance, placental development or psychological stressors. This suggests that the site visit 
committee, as prior research has also shown (Travis and Collins 1991), preferred traditional rather than new research agendas on premature birth.

An analysis of the Placental Function team's meeting discussions during the first year shows how the researchers reflected on and challenged the site visit committee's definition of premature birth. The team used the meetings to try to translate knowledge that was important to them to others so they too could see its relevance (Callon 1986). Within the center, there were many who understood the team's critique of the committee's problem definition and even identified the misalignment between the evaluation procedures and the transdisciplinary goals. Yet, as the center was dependent on financial support from the foundation, these discussions did not lead to a shared goal of better understanding preeclampsia.

\section{SITE VISIT: EXCLUDING PREECLAMPSIA FROM THE RESEARCH AGENDA}

At the end of the first year of funding, the foundation requested an annual report that explained the center's scientific progress. It also organized a site visit during which members of the center gave presentations on their ongoing work. The site visit committee was not pleased to find that despite their decision to eliminate the Placental Function team at the proposal stage, the team had received funding for the first year. At the site visit, the Placental Function team was the last to present of the four research areas. The principal investigator knew he was facing a challenging audience and that his team was likely to lose their funding. Similarly as in the team meetings, he insisted that premature birth was a complex syndrome and that in order to rigorously study it, the center's research agenda should include various projects, including developing a better understanding of the placenta's role at a cellular level.

After his presentation, the site visit committee had a couple of difficult questions, but the hardest critique, and deathblow, was presented in the written review after the site visit. When discussing the written review in a leadership meeting, one of the center leaders stated: "They [members of the 
committee] were pissed off that we did not follow exactly what they wanted us to do, which was to eliminate the Placental Function from the get go: "Well, we told you once before, and now we are telling you again.” [ID-27; Leadership; 051612]"

Despite the termination of the Placental Function team, discussions on the relevance of preeclampsia continued in the center-wide meetings. One leader noted that the site visit committee "just doesn't like the focus on preeclampsia" and "they think the myometrium is where the issue is" [ID-27; Leadership; 053012]. ${ }^{\text {iv }}$ The same center leader stated in another meeting after the first year's review: "So I think the placenta is important, but I don't think we can have it as a major research area just because of the politics of this grant and the people involved. [ID-27; Leadership; 053012]" The difficulties he referred to were discrepancies between the committee's ideas on what might cause premature birth and the hypotheses the members of the center considered worth pursuing. Some strongly disagreed with the committee's instruction to disregard the focus on preeclampsia:

I have to say there's not unanimity of opinion as to whether one should investigate things like preeclampsia, because their actual reason for the prematurity is iatrogenic in the sense that the baby is delivered, yet the process is still delivering a premature baby. So while I would not want to argue back with the evaluators who are going to make decisions about our funding, I don’t think we ought to necessarily give up completely this phenomenon, because it is significant. [ID31; Investigators; 062012]

This senior scientist made the same argument as members of the Placental Function team when they proposed to study preeclampsia: early delivery leads to premature babies and the health problems these babies face are the same whether the birth is spontaneous or medically induced. The scientist acknowledged that the center had to act according to the feedback of those who decide on funding, but felt that, from the perspective of solving the problem of premature birth, they should not abandon 
important research areas only because they were told to do so. A member of the leadership group responded to the comment by stating that he agreed that preeclampsia was worth studying: "I agree with you, it [preeclampsia] is a part of the premature birth story. It is one of the phenotypes. [ID-27; Investigators; 062012]" However, in order to maintain good working relations with the foundation and its site visit committee, the center had to follow the recommendations or, at least, give the impression that they were obedient.

In an interview conducted two years after the formation of the center, the same leader continued to reflect on the topic of preeclampsia: "I still believe that this area is relevant to what we are trying to get solved, it just has to be discrete [from the foundation and the site visit committee]. Otherwise, they [preeclampsia related projects] will be targeted for elimination based upon the biases of more traditional thinking people. [ID-27]" What the leader had learned from the Placental Function project was that there was no use to showcase preeclampsia related projects as those projects would not stand a chance with the site visit committee, which, he thought, consisted of "more traditional thinking people." It was better to support those projects through other funds, which then meant that they would not have to be included in the annual progress reports.

The site visit committee had the power to question the research agendas of those scientists who wanted to approach new lines of research. This case also demonstrates that researchers could challenge this power by making it seem as though the site visit committee's decisions were being followed. The plan was to continue to work on preeclampsia related projects, but through other funds, which meant those research efforts could be excluded from the progress reports. As research outcomes are what matter in the end, the leader noted: "If the center actually discovered something that can predict and ultimately intervene and protect against preeclampsia, which kills women and babies and creates premature birth all over the world. I bet you anything that the foundation would take credit for it." 


\section{DISCUSSION}

This study examined the relationship between unconventional research agendas and academic evaluation by tracking the development of one transdisciplinary team. The study asked how researchers develop unconventional research agendas and make sense of the actions of a site visit committee organized to advise a research funder. When the object of evaluation is in some way unconventional, identifying scientific excellence is often problematic (Porter and Rossini 1985; Travis and Collins 1991). The tension between unconventional research agendas and evaluation procedures can lead to competing claims about myriad things: for example, methods, data, concepts, or hypotheses. This study revealed how the researchers pushed the boundaries around premature birth and became disappointed by the site visit committee's definition of the problem. As such, the study highlighted the competing ways of defining what counts as a legitimate research focus.

The process narrative on the team's development covered three stages: proposal stage, after evaluation, and site visit. At the proposal stage, the researchers sought to develop unconventional research agendas that could provide new insights into premature birth. The members of the center assumed that the boundaries around the problem were elastic; that was the impression the leaders had gotten from their discussions with the representatives of the foundation who had emphasized transdisciplinary research approach. Although the researchers knew and had personally experienced that there were existing scholarly communities that had particular understandings of premature birth-the principal investigator of the team noted this in an interview - they thought the purpose was to consider premature birth beyond the established lines of research.

Given this, the aftermath of the first evaluation was surprising to the members of the Center. When asked in an interview what had surprised him the most in putting together the transdisciplinary research center, one leader said: "I think the only surprise is how the site visit panel has affected the working of the center, how the panel was put together, and how much of an impact it has actually had. 
That was surprising to me. I expected a different kind of panel. [ID-27]" Considering the exploratory nature of the new transdisciplinary research center, the scientists expected to have a site visit committee with less formal power to decide on the research agenda. Scientists criticized the committee's inclination to draw boundaries around a complex health problem, because the reason for forming the center was that prior research on premature birth had not succeeded in determining the causes of the syndrome. As preeclampsia became a forbidden topic, the set of available research problems and hypotheses within the whole center became restricted.

Despite the power of the site visit committee on transdisciplinary discovery in the center's early stages, we also saw how the scientists challenged the committee's statements in their shared meetings. In an effort to gain intellectual support for their research agenda, the scientists discussed how preeclampsia related to premature birth and how heterogeneous the syndrome was. Beyond these meeting interactions, however, the scientists could not do much to challenge the site visit committee's decision. The site visit committee had the power to determine which center projects were going to receive funding the following year.

Although a site visit committee can shape how scientists define research problems, its power is not infinite as there are multiple funders with possibly different evaluative standards. To manage the power of the site visit committee, the center leaders found other funds for supporting preeclampsia related, more unconventional, research. The leaders realized, however, that it was not enough to find other resources; they would also need to hide research that related to preeclampsia from the foundation and its site visit committee. Therefore, shining light on some research projects and leaving others in the dark can be a strategy for developing unconventional research agendas. Leisyte et al. (2010) saw thisgiving the impression as though rules are being followed - as one way in which researchers can challenge the power of peer review. 
Some might claim that in the context of the center, the foundation did not do a proper job in selecting a site visit committee that understood their objective to fund new lines of research on premature birth. This is a fair conclusion, which leads to the question, is traditional discipline-based peer review a useful tool in the development of innovative, transdisciplinary research agendas? The concern has been that peer reviewers might intentionally or unintentionally favor research that is familiar to them. If this were the case, peer reviewers would assess research that differed from mainstream topics and approaches less favorably (Lee et al. 2013). In this study, one leader pointed out that the site visit committee immediately promoted research on uterine contractions and the cervix even though these were seen as research areas with long histories.

According to Lee (2015), there is a need to articulate what the aims of science are in different contexts and then consider how those aims should inform peer review practices and the recognition of scientific excellence. If funding agencies want to promote cross-disciplinary and innovative science, it is worth considering to what extent their evaluation procedures can ensure that quality in such research proposals is recognized. Concerning unconventional research proposals, Langfeldt (2006) has stated that the peer review system should be adjusted to a more risk-taking mode that allows for the identification of potential in proposals that include exploratory elements. Figuring out how to do this in practice should be of interest to all funding agencies interested in investing in transdisciplinary discovery on longstanding problems. 


\section{REFERENCES}

Barré, Remi. 2010. “Towards Socially Robust S\&T Indicators: Indicators Are Debatable Devices, Enabling Collective Learning." Research Evaluation 19 (3): 227-231.

Barry, David, Brigid Carroll, and Hans Hansen. 2006. "To Text or Context? Endotextual, Exotextual, or Multi-textual Approaches to Narrative and Discursive Organizational Studies." Organization Studies 27 (8): 1091-1110.

Becher, Toby, and Paul R. Trowler. 2001. Academic Tribes and Territories. Philadelphia, PA: The Society for Research into Higher Education and Open University Press.

Bianco, Mariela, Natalia Gras, and Judith Sutz. 2016. “Academic Evaluation: Universal Instrument? Tool for Development?" Minerva 54 (4): 399-421.

Boix Mansilla, Veronica. 2006. "Interdisciplinary Work at the Frontier: An Empirical Examination of Expert Interdisciplinary Epistemologies." Issues in Integrative Studies 24: 1-31.

Braben, Donald W. 2004. Pioneering Research: A Risk Worth Taking. Hoboken, NJ: WileyInterscience.

Callon, Michel. 1986. "Some Element of a Sociology of Translation: Domestication of the Scallops and the Fishermen of St Brieuc Bay." In Power, Action, and Belief: A New Sociology of Knowledge?, edited by John Law, 196-233. London, UK: Routledge \& Kegan Paul. 
Chubin, Daryl E., and Edward J. Hackett. 1990. Peerless Science. Peer Review and U.S. Science Policy. Albany, NY: State University of New York Press.

Corbin, Juliet, and Anselm Strauss. 2008. Basics of Qualitative Research. Thousand Oaks, CA: Sage.

Daniel, Hans-Dieter, Sandra Mittag, and Lutz Bornmann. 2007. "The Potential and Problems of Peer Evaluation in Higher Education and Research.” In Quality Assessment for Higher Education in Europe, edited by Alessandro Cavalli, 71-82. London, UK: Portland Press.

Ebadi, Ashkan, and Andrea Schiffauerova. 2015. "How to Receive More Funding for Your Research? Get Connected to the Right People!” PLoS ONE 10 (7): e0133061. doi:10.1371/journal.pone.0133061

Foucault, Michel. 1977. Discipline and Punish. Harmondsworth, UK: Penguin.

Foucault, Michel. 1983. “Afterword: The Subject and Power.” In Michel Foucault: Beyond Structuralism and Hermeneutics, edited by Hubert L. Dreyfus and Paul Rabinow, 208-226. Chicago, IL: University of Chicago Press.

Gallo, Stephen A., Joanne H. Sullivan, and Scott R. Glisson. 2016. “The Influence of Peer Reviewer Expertise on the Evaluation of Research Funding Applications.” PLoS ONE 11 (10): e0165147. doi:10.1371/journal.pone.0165147 
Gillespie, Gilbert W., Daryl E. Chubin, and George M. Kurzon. 1985. "Experience with NIH Peer Review: Researchers' Cynicism and Desire for Change.” Science, Technology, \& Human Values 10 (3): $44-54$.

Gläser, Jochen, and Grit Laudel. 2007. Evaluation without Evaluators: The Impact of Funding Formulae on Australian University Research. In The Changing Governance of the Sciences. The Advent of Research Evaluation Systems, edited by Richard Whitley and Jochen Gläser, 127-151. Dordrecht, Netherlands: Springer,

Heracleous, Loizos, and John Hendry. 2000. "Discourse and the Study of Organization: Toward a Structurational Perspective.” Human Relations 53 (10): 1251-1286.

Huutoniemi, Katri. 2012. "Communicating and Compromising on Disciplinary Expertise in the Peer Review of Research Proposals.” Social Studies of Science 42 (6): 897-921.

Jacobs, Jerry A., and Scott Frickel. 2009. "Interdisciplinarity: A Critical Assessment.” Annual Review of Sociology 35: 43-65.

Knorr-Cetina, Karin. 1999. Epistemic Cultures: How the Sciences Make Knowledge. Cambridge, MA: Harvard University Press.

Kuhn, Thomas. 1970. The Structure of Scientific Revolutions. Chicago, IL: University of Chicago Press. 
Lamont, Michèle. 2009. How Professors Think. Inside the Curious World of Academic Judgment. Cambridge, MA: Harvard University Press.

Lamont, Michèle, and Katri Huutoniemi. 2011. “Comparing Customary Rules of Fairness: Evaluative Practices in Various Types of Peer Review Panels." In Social Knowledge in the Making, edited by Charles Camic, Neil Gross, and Michèle Lamont, 209-232. Chicago, IL: University of Chicago Press.

Lamont, Michèle. 2012. “Toward a Comparative Sociology of Valuation and Evaluation.” Annual Review of Sociology 38: 201-221.

Langfeldt, Liv. 2001. "The Decision-Making Constraints and Processes of Grant Peer Review, and Their Effects on the Review Outcome." Social Studies of Science 31 (6): 820-841.

Langfeldt, Liv. 2004. "Expert Panels Evaluating Research: Decision-Making and Sources of Bias.” Research Evaluation 13 (1): 51-62.

Langfeldt, Liv. 2006. “The Policy Challenges of Peer Review: Managing Bias, Conflict of Interests and Interdisciplinary Assessments.” Research Evaluation 15 (1): 31-41.

Langfeldt, Liv, and Svein Kyvik. 2010. "Researchers as Evaluators: Tasks, Tensions and Politics." Higher Education 62 (2): 199-212.

Lee, Carole J., Cassidy R. Sugimoto, Guo Zhang, and Blaise Cronin. 2013. "Bias in Peer Review." Journal of the American Society for Information Science and Technology 64 (1): 2-17. 
Lee, Carole J. 2015. “Commensuration Bias in Peer Review.” Philosophy of Science 82 (5): 12721283.

Leisyte, Liudvika, Jürgen Enders, and Harry de Boer. 2010. "Mediating Problem Choice: Academic Researchers' Responses to Changes in their Institutional Environment." In Reconfiguring Knowledge Production: Changing Authority Relationships in the Sciences and their Consequences for Intellectual Innovation, edited by Richard Whitley, Jochen Gläser, and Lars Engwall, 266-290. Oxford, UK: Oxford University Press.

Lofland, John, and Lyn H. Lofland. 1995. Analyzing Social Settings. Belmont, CA: Wadsworth.

Luukkonen, Terttu. 2012. "Conservatism and Risk-Taking in Peer Review: Emerging ERC Practices." Research Evaluation 21 (1): 48-60.

Luukkonen, Terttu, and Duncan A. Thomas. 2016. "The 'Negotiated Space' of University Researchers' Pursuit of Research Agenda.” Minerva 54 (1): 99-127.

Maasen, Sabine, and Olivier Lieven. 2006. "Transdisciplinarity: A New Mode of Governing Science?" Science and Public Policy 33 (6): 399-410.

Maines, David R. 1993. “Narrative’s Moment and Sociology’s Phenomena: Toward a Narrative Sociology." The Sociological Quarterly 34 (1): 17-38. 
Mallard, Gregoire, Michèle Lamont, and Joshua Guetzkow. 2009. "Fairness as Appropriateness. Negotiating Epistemological Differences in Peer Review.” Science, Technology, \& Human Values 34 (5): 573-606.

McCullough, Jim. 1989. "First Comprehensive Survey of NSF Applicants Focuses on their Concerns about Proposal Review.” Science, Technology, \& Human Values 14 (1): 78-88.

Merton, Robert. 1942. "The Normative Structure of Science.” In The Sociology of Science. Chicago, IL: University of Chicago Press.

Meskus, Mianna, Luca Marelli, and Giuseppe D’Agostino. 2018. "Research Misconduct in the Age of Open Science. The Case of STAP Stem Cells.” Science as Culture 27 (1): 1-23.

National Institutes of Health. 2013. About NIH: Mission. http://nih.gov/about/mission.htm.

National Science Foundation. 2013. NSF at a Glance. http://www.nsf.gov/about/glance.jsp.

Overbeke, John, and Elizabeth Wagner. 2003. "The State of the Evidence: What We Know and What We Don't Know about Journal Peer Review.” In Peer Review in Health Sciences, edited by Fiona Godlee and Tom Jefferson, 45-61. London, UK: BMJ Books.

Polkinghorne, Donald E. 1988. Narrative Knowing and the Human Sciences. Albany, NY: State University of New York Press. 
Porter, Alan L., and Frederick A. Rossini. 1985. "Peer-Review of Interdisciplinary Research Proposals." Science, Technology, \& Human Values 10 (3): 33-38.

Roelofs, Joan. 2015. "How Foundations Exercise Power.” The American Journal of Economics and Sociology 74 (4): 654-675.

Schneider, William H. 2015. "The Origin of the Medical Research Grant in the United States: The Rockefeller Foundation and the NIH Extramural Funding Program." Journal of the History of Medicine and Allied Sciences 70 (2): 279-311.

Shore, Cris, and Susan Wright. 2000. "Coercive Accountability. The Rise of Audit Culture in Higher Education." In Audit Cultures. Anthropological Studies in Accountability, Ethics, and the Academy, edited by Marilyn Strathern, 57-89. London, UK: Routledge.

Smith, Elta. 2009. "Imaginaries of Development: The Rockefeller Foundation and Rice Research.” Science as Culture 18 (4): 461-482.

Strauss, Anselm L., Leonard Schatzman, Danuta Ehrlich, Rue Bucher, and Melvin Sabshin. 1963. "The Hospital and Its Negotiated Order.” In The Hospital in Modern Society, edited by Eliot Friedson, 147169. Glencoe, NY: Free Press.

Strauss, Anselm. 1987. Qualitative Analysis for Social Scientists. Cambridge, UK: Cambridge University Press. 
Travis, G.D.L., and H.M. Collins. 1991. "New Light on Old Boys: Cognitive and Institutional Particularism in the Peer Review System.” Science, Technology, \& Human Values 16 (3): 322-341.

van der Laan, Anna Laura, and Marianna Boenink. 2015. "Beyond Bench and Bedside: Disentangling the Concept of Translational Research.” Health Care Analysis 23 (1): 32-49.

Weller, Ann C. 2001. Editorial Peer Review: Its Strengths and Weaknesses. Medford, NJ: Information Today.

Wessely, Simon. 1998. “Peer Review of Grant Applications: What Do We Know?” Lancet 352 (9124): 301-305.

Whitley, Richard. 2010. "Reconfiguring the Public Science: The Impact of Governance Changes on Authority and Innovation in Public Science Systems." In Reconfiguring Knowledge Production: Changing Authority Relationships in the Sciences and their Consequences for Intellectual Innovation, edited by Richard Whitley, Jochen Gläser, and Lars Engwall, 3-47. Oxford, UK: Oxford University Press.

Ziman, John. 1994. Prometheus Bound. Science in a Dynamic Steady State. Cambridge, UK: Cambridge University Press. 


\section{TABLES}

Table 1: Data sources.

\begin{tabular}{|l|l|}
\hline Data Source & \\
\hline Placental Function team meeting & 4 in total \\
recordings and transcripts & Length of meetings: 60-75 min \\
recordings and transcripts & 16 in total \\
\hline Onterviews with members of the & Length of meetings: 60-90 min \\
Placental Function team and & Fength of transcripts: $45-55$ pages \\
leadership & scientists \\
\hline Secondary sources & Second round: 4 leaders, 1 admin, \\
& Eveaders, 1 admin, 4 \\
& Length: 60-120 minutes \\
\hline
\end{tabular}




\section{FIGURES}

Figure 1: Analytical stages in chronological order.

\begin{tabular}{|c|c|c|}
\hline $\begin{array}{l}\text { 1: Analysis of the } \\
\text { research proposal } \\
\text { and its assessment: } \\
\text { documents and } \\
\text { interviews }\end{array}$ & $\begin{array}{l}\text { 2: Analysis of } \\
\text { scientific meeting } \\
\text { discussions: } \\
\text { recordings and } \\
\text { transcripts }\end{array}$ & $\begin{array}{l}\text { 3: Analysis of the } \\
\text { progress report and } \\
\text { its assessment: } \\
\text { documents and } \\
\text { interviews }\end{array}$ \\
\hline
\end{tabular}

\section{NOTES}

${ }^{\mathrm{i}}$ From now on, the two partners are identified as the center and the foundation.

ii Implantation is the process whereby the embryo adheres to the wall of the uterus.

iii I did not attend the site visit where the proposal was reviewed, but in the interviews I asked scientists, what it was like and how their proposal was received. I have also analyzed the written review from the panel.

iv Myometrium is the middle layer of the uterine wall.

\section{Author Biography}

Elina I. Mäkinen is an Associate Professor in the Faculty of Management and Business and the New Social Research program at Tampere University, Finland. She is an organizational researcher who draws on qualitative methods and process research approach to understand collaborative processes at different knowledge and occupational boundaries. She received her Ph.D. in organization studies from Stanford University. Her research has appeared in journals such as Science, Technology, \& Human Values, Science as Culture, and Informing Science.

\section{Acknowledgements}

I am grateful for Daniel McFarland, Woody Powell, Karen Cook, John Willinsky, and Charles Gomez for their thoughtful feedback on an earlier draft of this work. I would also like to thank my colleagues at the Institute for Advanced Social Research and the New Social Research program at Tampere University as well as the editor and two anonymous reviewers for their critical and detailed feedback. 